\title{
Catalytic Ozonation of Phenol in Aqueous Solution by $\mathrm{Co}_{3} \mathrm{O}_{4} \mathrm{Nanoparticles}$
}

\author{
Yuming Dong, ${ }^{*}$ Guangli Wang, Pingping Jiang, Aimin Zhang, ${ }^{\dagger, *}$ Lin Yue, ${ }^{\ddagger}$ and Xiaoming Zhang \\ School of Chemical and Material Engineering, Jiangnan University, Wuxi 214122, P. R. China \\ ${ }^{*}$ E-mail:dongym@jiangnan.edu.cn \\ 'School of Chemistry and Chemical Engineering, Key Laboratory of Mesoscopic Chemistry, Nanjing University, Nanjing \\ 210093, P. R. China. *E-mail: zhangam@nju.edu.cn \\ ${ }^{\ddagger}$ School of Food Science and Technology, Jiangnan University, Wuxi 214122, P. R. China \\ Received June 14, 2010, Accepted August 20, 2010
}

\begin{abstract}
The degradation efficiencies of phenol in aqueous solution were studied by semi-continuous experiments in the processes of ozone alone, ozone/bulky $\mathrm{Co}_{3} \mathrm{O}_{4}$ and ozone $/ \mathrm{Co}_{3} \mathrm{O}_{4}$ nanoparticles. Catalyst samples (bulky $\mathrm{Co}_{3} \mathrm{O}_{4}$ and $_{\mathrm{Co}_{3}} \mathrm{O}_{4}$ nanoparticles) were characterized by X-ray diffraction and transmission electron microscopy. The Brunauer-EmmettTeller surface area, $\mathrm{pH}_{\mathrm{pzc}}$ and the density of surface hydroxyl groups of the two catalyst samples were also measured. The catalytic activity of $\mathrm{Co}_{3} \mathrm{O}_{4}$ nanoparticles was investigated for the removal of phenol in aqueous solutions under different reaction temperatures. Tert-butyl alcohol had little effect on the catalytic ozonation processes. Based on these results, the possible catalytic ozonation mechanism of phenol by $\mathrm{Co}_{3} \mathrm{O}_{4}$ nanoparticles was proposed as a reaction process between ozone molecules and pollutants.
\end{abstract}

Key Words: Cobalt oxide, Catalytic degradation, Nano-catalyst, Catalytic mechanism

\section{Introduction}

Aromatic compounds are known pollutants in the effluents of several industries. Among these compounds, phenol is a typical compound produced in the petrochemical, chemical and pharmaceutical industries. Phenol has been classified as a priority pollutant in the USEPA (United States Environmental Protection Agency) list for its highly toxic, carcinogenic, mutagenic, teratogenic properties. Recently, considerable attention has been paid to chemical degradation of phenol. ${ }^{1,2}$

Ozone, due to its high oxidation ability, has been widely used for the removal of organic pollutants. Single ozonation, in which ozone is used alone for pollutants degradation, organic compounds can not be oxidized quickly and the utilization efficiency of ozone is low. As a result, the single ozonation for water treatment needs a large amount of ozone, which greatly limits its practical application. To overcome the drawback, catalytic ozonation using catalysts to improve degradation efficiency emerged. Catalytic ozonation includes homogeneous catalytic ozonation and heterogeneous catalytic ozonation. Compared with the homogeneous catalytic process, the heterogeneous catalytic ozonation has a notable advantage of no secondary pollutants and is now attracting more and more attention. ${ }^{3,4}$

Nanomaterials, which can exhibit unusual chemical and physical properties, are novel and promising heterogeneous ozonation catalysts in environment research. ${ }^{5-11}$ For instance, Jung and co-workers investigated the catalytic ozonation properties of many nanomaterials (including commercial $\mathrm{ZnO}$, biotic and abiotic prepared iron oxide, biogenic magnetite) and found that nano-catalysts are potentially highly efficient catalysts due to their high surface area and well dispersivity. ${ }^{5-7}$

As an important functional material, $\mathrm{Co}_{3} \mathrm{O}_{4}$ has been widely studied as heterogeneous catalysts, anode materials in $\mathrm{Li}$ ion rechargeable batteries, solid-state sensors, electrochemical de- vices etc. However, the study on $\mathrm{Co}_{3} \mathrm{O}_{4}$ used as ozonation catalyst was rare. ${ }^{11}$ The revelation of catalytic mechanism is very important for understanding the catalysis process and, even more importantly, for designing efficient nano-catalysts. In this paper, the surface chemistry and the catalytic property of $\mathrm{Co}_{3} \mathrm{O}_{4}$ nanomaterials were investigated in detail to illuminate the mechanism of catalytic ozonation for the degradation of phenol in aqueous solution. Our research may be a motivation for fundamental understanding and a promotion for application of novel catalytic materials.

\section{Experimental}

Chemicals. All chemicals used were of analytical grade without further purification. All aqueous solutions were prepared using distilled water. $\mathrm{Co}\left(\mathrm{CH}_{3} \mathrm{COO}\right)_{2} \cdot 4 \mathrm{H}_{2} \mathrm{O}, 25 \%$ ammonia and phenol were supplied by the Sinopharm Chemical Reagent Company.

Preparation of $\mathrm{Co}_{3} \mathrm{O}_{4}$ samples. The $\mathrm{Co}_{3} \mathrm{O}_{4}$ nanomaterials were prepared according to a hydrothermal method proposed by our group. ${ }^{11}$ In a typical procedure, $0.50 \mathrm{~g}$ of $\mathrm{Co}\left(\mathrm{CH}_{3} \mathrm{COO}\right)_{2}$. $4 \mathrm{H}_{2} \mathrm{O}$ was dissolved in $25.0 \mathrm{~mL}$ of water, and $2.5 \mathrm{~mL}$ of $25 \%$ ammonia was added under vigorous stirring. The mixture was stirred in air for about $10 \mathrm{~min}$ to form homogeneous fuscous slurry. Then the suspension was transferred into a $48.0 \mathrm{~mL}$ of autoclave, sealed and maintained at $423 \mathrm{~K}$ for $3 \mathrm{~h}$. After this, the autoclave was cooled to room temperature naturally. The black solid products were washed with water via centrifugationredispersion, dried at $383 \mathrm{~K}$ for $4 \mathrm{~h}$.

Bulky $\mathrm{Co}_{3} \mathrm{O}_{4}$ was prepared through a pyrogenation route. In our experiment, $\mathrm{Co}\left(\mathrm{CH}_{3} \mathrm{COO}\right)_{2} \cdot 4 \mathrm{H}_{2} \mathrm{O}$ was calcined at $1073 \mathrm{~K}$ for $4 \mathrm{~h}$ under air atmosphere. Then, the product was cooled to room temperature naturally, crushed and sieved into 100 mesh size. 
Characterization of $\mathrm{Co}_{3} \mathrm{O}_{4}$ samples. The compositions and phases of the products were identified by powder X-ray diffraction (XRD) on an X'TRA X-ray diffractometer (ARL, Switzerland) using $\mathrm{Cu} \mathrm{K} \alpha$ radiation ( $\lambda=1.5418 \AA$ ). The morphologies and sizes of the products were examined by transmission electron microscopy (TEM) with a JEM-200CX (JEOL, Japan) transmission electron microscope at an accelerating voltage of $200 \mathrm{kV}$.

The nitrogen adsorption and desorption isotherms at $77 \mathrm{~K}$ were measured using an ASAP2020 surface area and porosity analyzer (Micromeritics, USA), and the degas conditions was $423 \mathrm{~K}$ for $3 \mathrm{~h}$. The Brunauer-Emmett-Teller (BET) specific surface area was calculated using isotherms data. The density of surface hydroxyl groups (expressed in mmol per unit gram), was measured according to a saturated deprotonation method. ${ }^{12-14}$ The $\mathrm{pH}_{\mathrm{pzc}}$ ( $\mathrm{pH}$ at which the surface is zero charged) was measured following a powder addition method. ${ }^{12,15,16}$

Catalytic ozonation procedure. The catalytic degradation of phenol was performed in a semi-continuous flow mode at $298 \mathrm{~K}$. Ozone was generated in a laboratory ozone generator using pure oxygen as gas source. The flow rate of oxygen was $15 \mathrm{~mL}$ $\mathrm{min}^{-1}$, and the flow rate of ozone was $0.40 \mathrm{mg} \mathrm{min}^{-1}$. In a typical catalytic degradation procedure, $0.50 \mathrm{~g}$ of $\mathrm{Co}_{3} \mathrm{O}_{4}$ and $200 \mathrm{~mL}$ of simulated wastewater (the initial concentration of phenol was $100 \mathrm{mg} \mathrm{L}^{-1}$ ) were mixed in a flask with stirring under thermostatic control (within $\pm 1 \mathrm{~K}$ ). Then, ozone was fed into the flask with continuous stirring. At given intervals, $3.0 \mathrm{~mL}$ of samples were taken from the reactor and centrifuged for analysis. Single ozonation were carried out using the similar procedure as catalytic ozonation without catalyst.

The concentrations of phenol, and its oxidized intermediates such as catechol, hydroquinone and p-benzoquinone were determined by a Waters 515 high performance liquid chromatography (HPLC, Waters, USA) with a reversed-phase $4.6 \mathrm{~mm} \times$ $250 \mathrm{~mm} \mathrm{C}_{18}$ waters column (Cosmosil, Japan) at room temperature. The elution was carried out by pumping the mixture of methanol and water $(6: 4, \mathrm{v} / \mathrm{v})$ at a flow rate of $1.0 \mathrm{~mL} \mathrm{~min}^{-1}$, and an attached Waters 2487 dual $\lambda U V$-vis absorbance detector (Waters, USA) was used. The wavelengths were set at 210, 274, 288 and $246 \mathrm{~nm}$ for the analysis of phenol, catechol, hydroquinone and p-benzoquinone, respectively.

\section{Results and Discussion}

Characterization of $\mathrm{Co}_{3} \mathrm{O}_{4}$ samples. The XRD patterns (Fig. 1) of the as-prepared $\mathrm{Co}_{3} \mathrm{O}_{4}$ nanoparticles (JCPDS 09-0418) and bulky $\mathrm{Co}_{3} \mathrm{O}_{4}$ (JCPDS 78-1970) indicated high purity of the products with face-centered cubic phase of $\mathrm{Co}_{3} \mathrm{O}_{4}$. In addition, all the diffraction peaks of $\mathrm{Co}_{3} \mathrm{O}_{4}$ nanomaterials were less sharp than those of bulky $\mathrm{Co}_{3} \mathrm{O}_{4}$, demonstrating the poorer crystallization degree and lower size of $\mathrm{Co}_{3} \mathrm{O}_{4}$ nanoparticles.

Fig. $2 \mathrm{a}$ and $\mathrm{b}$ show the TEM images of $\mathrm{Co}_{3} \mathrm{O}_{4}$ nanoparticles and bulky $\mathrm{Co}_{3} \mathrm{O}_{4}$ respectively. It can be found that, the products by the hydrothermal method were uniform nanoparticles with average size about $20 \mathrm{~nm}$, and the products by the pyrogenation method were particles with average size above $200 \mathrm{~nm}$. According to the results of the nitrogen adsorption and desorption isotherms, the BET surface area of $\mathrm{Co}_{3} \mathrm{O}_{4}$ nanoparticles was
$119.85 \mathrm{~m}^{2} \mathrm{~g}^{-1}$, and that of bulky $\mathrm{Co}_{3} \mathrm{O}_{4}$ was $0.65 \mathrm{~m}^{2} \mathrm{~g}^{-1}$. The $\mathrm{pH}_{\mathrm{pzc}}$ of $\mathrm{Co}_{3} \mathrm{O}_{4}$ nanoparticles was 6.30 , and that of bulky $\mathrm{Co}_{3} \mathrm{O}_{4}$ was 3.75. The density of surface hydroxyl groups of $\mathrm{Co}_{3} \mathrm{O}_{4}$ nanoparticles was $3.90 \times 10^{-3} \mathrm{~mol} \mathrm{~g}^{-1}$, while that of bulky $\mathrm{Co}_{3} \mathrm{O}_{4}$ was $4.26 \times 10^{-5} \mathrm{~mol} \mathrm{~g}^{-1}$. Obviously, the two $\mathrm{Co}_{3} \mathrm{O}_{4}$ samples obtained by different preparation processes had different crystallization degree, particles size and surface properties.

Catalytic degradation efficiency for Ozonation of Phenol. Fig. 3 (A) shows the degradation of phenol at different ozonation

(a)

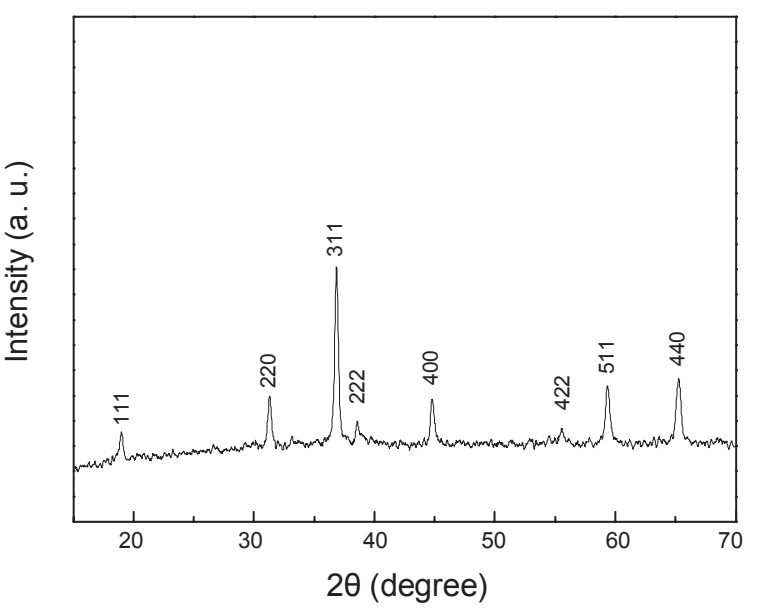

(b)

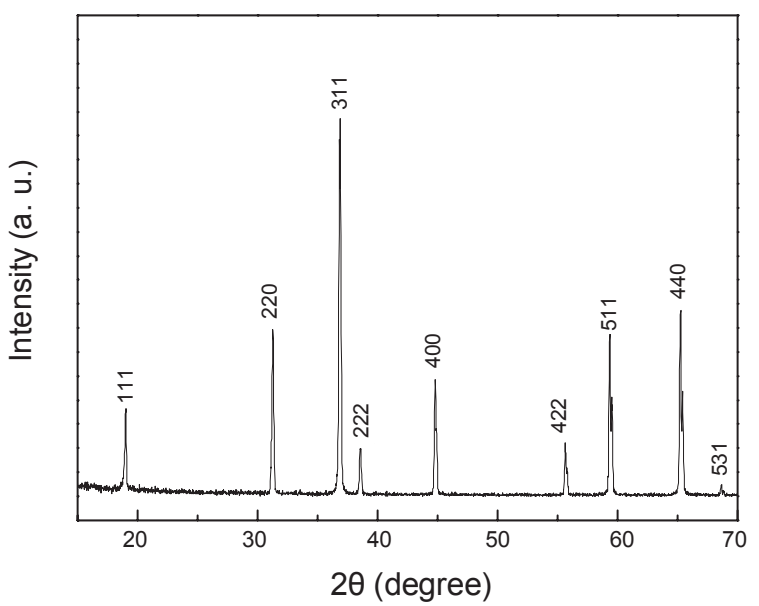

Figure 1. $\mathrm{XRD}$ patterns of $\mathrm{Co}_{3} \mathrm{O}_{4}$ nanoparticles (a) and bulky $\mathrm{Co}_{3} \mathrm{O}_{4}$ (b)
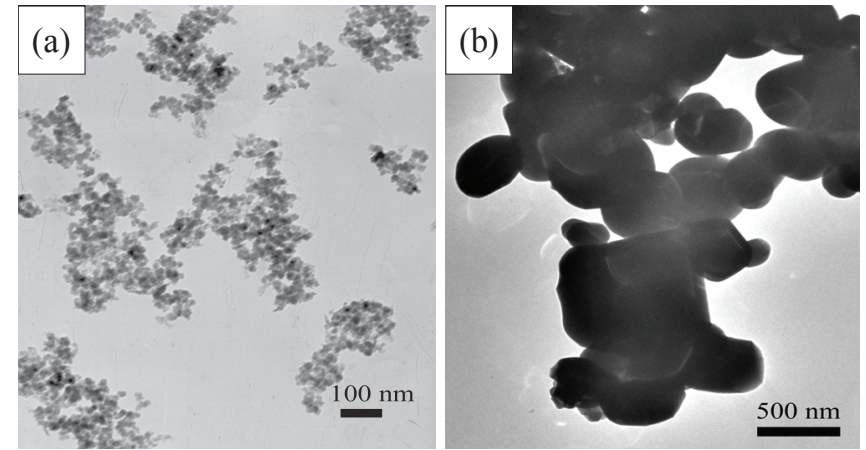

Figure 2. TEM images of $\mathrm{Co}_{3} \mathrm{O}_{4}$ nanoparticles (a) and bulky $\mathrm{Co}_{3} \mathrm{O}_{4}$ (b) 
(A)

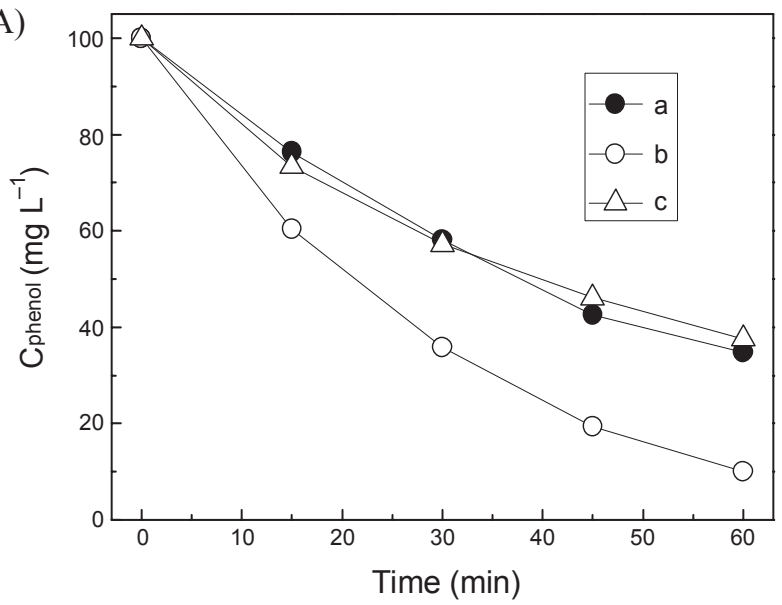

(C)

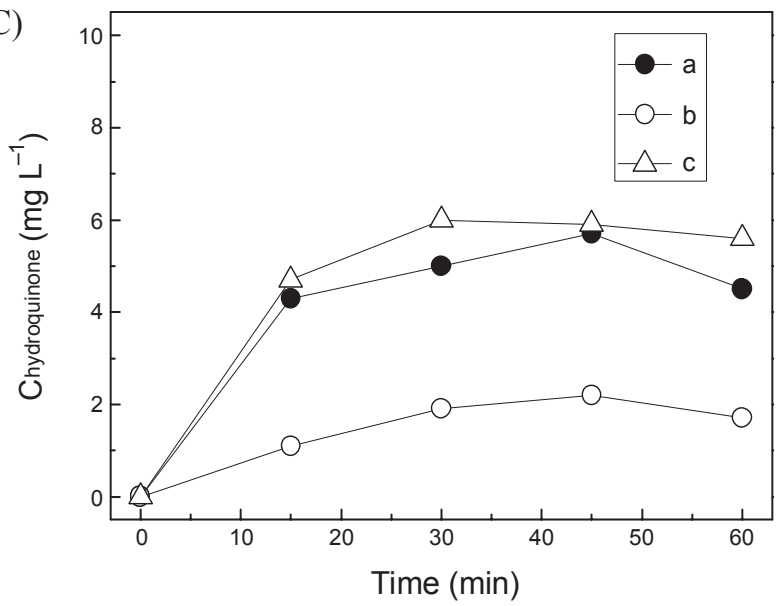

(B)

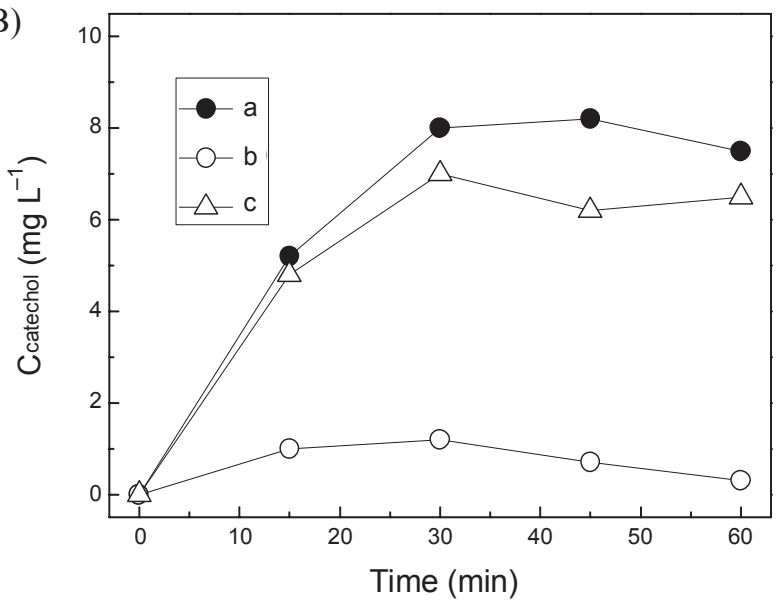

(D)

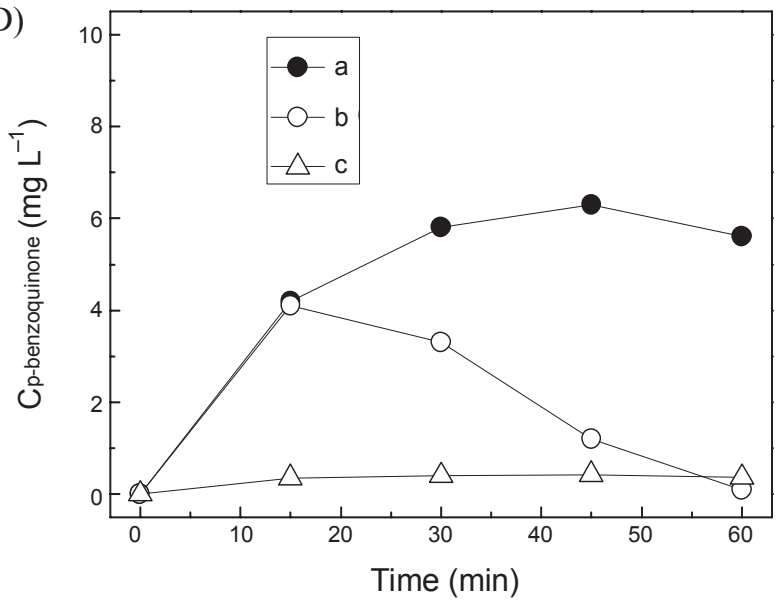

Figure 3. Time evolution of the concentration of phenol (A), catechol (B), hydroquinone (C) and p-benzoquinone (D) under single ozonation (a), catalytic ozonation of $\mathrm{Co}_{3} \mathrm{O}_{4}$ nanomaterials (b) and catalytic ozonation of bulky $\mathrm{Co}_{3} \mathrm{O}_{4}$ (c). Catalyst dose: $0.50 \mathrm{~g}$, volume of simulated wastewater: $200 \mathrm{~mL}$, initial concentration of phenol: $100 \mathrm{mg} \mathrm{L}^{-1}$, flow rate of ozone: $0.40 \mathrm{mg} \mathrm{min}^{-1}$, reaction temperature: $298 \mathrm{~K}$

time in single ozonation and catalytic ozonation with $\mathrm{Co}_{3} \mathrm{O}_{4}$ nanoparticles or bulky $\mathrm{Co}_{3} \mathrm{O}_{4}$. It can be clearly seen that $\mathrm{Co}_{3} \mathrm{O}_{4}$ nanoparticles demonstrated remarkably high catalysis efficiency on the ozonation degradation of phenol, while bulky $\mathrm{Co}_{3} \mathrm{O}_{4}$ hardly showed any catalysis effect. For example, the residual concentration of phenol was $34.7 \mathrm{mg} \mathrm{L}^{-1}$ after single ozonation of $60 \mathrm{~min}$, while it was merely $10.0 \mathrm{mg} \mathrm{L}^{-1}$ in presence of $\mathrm{Co}_{3} \mathrm{O}_{4}$ nanomaterials. Compared with single ozonation, the degradation efficiency of phenol increased about $37.8 \%$ in presence of the nano-catalyst.

Before being degraded to small organic acids, phenol is easily oxidized to more toxic intermediates such as catechol, hydroquinone and p-benzoquinone. ${ }^{17-22}$ The time dependent concentrations of these intermediates in the single ozonation and the catalytic ozonation were investigated. The results are shown in Fig. 3B, C and D. It can be found that, the concentrations of these intermediates in the catalytic ozonation by nano-catalyst were lower than that in single ozonation at the same ozonation time. At the ozonation of $60 \mathrm{~min}$, the concentrations of catechol, hydroquinone and p-benzoquinone in catalytic ozonation by $\mathrm{Co}_{3} \mathrm{O}_{4}$ nanoparticles were $0.3,1.7$ and $0.1 \mathrm{mg} \mathrm{L}^{-1}$, respectively, while those in single ozonation were $7.5,4.5$ and $5.6 \mathrm{mg} \mathrm{L}^{-1}$. That is, the total residual concentration of the three intermediates in the presence of the nano-catalyst was only $11.9 \%$ of that without catalyst. The results indicated that, besides the removal of phenol, the $\mathrm{Co}_{3} \mathrm{O}_{4}$ nano-catalyst was also helpful for the degradation of these toxic intermediates. As for the ozonation in the presence of bulky $\mathrm{Co}_{3} \mathrm{O}_{4}$, the residual concentrations of catechol, hydroquinone and p-benzoquinone were 6.5, 5.6 and 0.4 $\mathrm{mg} \mathrm{L}^{-1}$ at $60 \mathrm{~min}$. Compared with single ozonation, the concentration of p-benzoquinone was decreased obviously, while the concentrations of catechol and hydroquinone were hardly affected by bulky $\mathrm{Co}_{3} \mathrm{O}_{4}$.

Influence of temperature. Operation temperature usually influences the ozonation degradation of organic pollutants. Besides $298 \mathrm{~K}$ (Fig. 3), the catalytic ozonation experiments using $\mathrm{Co}_{3} \mathrm{O}_{4}$ nano particles were also carried out at 283 and 313 K (Fig. 4). Compared with the results at $298 \mathrm{~K}$ (Fig. 3A), the degradation rates of phenol at 283 and $313 \mathrm{~K}$ were lower.

Ozone is very unstable in water. The rise of temperature can influence the catalytic ozonation process in three ways: (1) the concentration of ozone in solution is reduced; (2) the transformation from ozone molecules to hydroxyl radicals is accelerated, and the degradation of phenol by hydroxyl radicals is faster than that by ozone molecules; ${ }^{23,24}$ (3) diffusion rate of the reacting substances is enhanced. Therefore the efficiency in the 
(A)

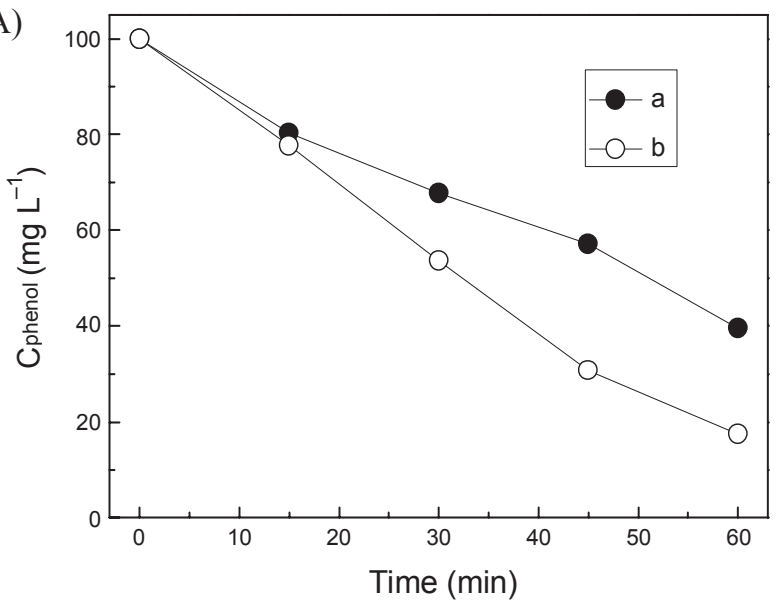

(B)

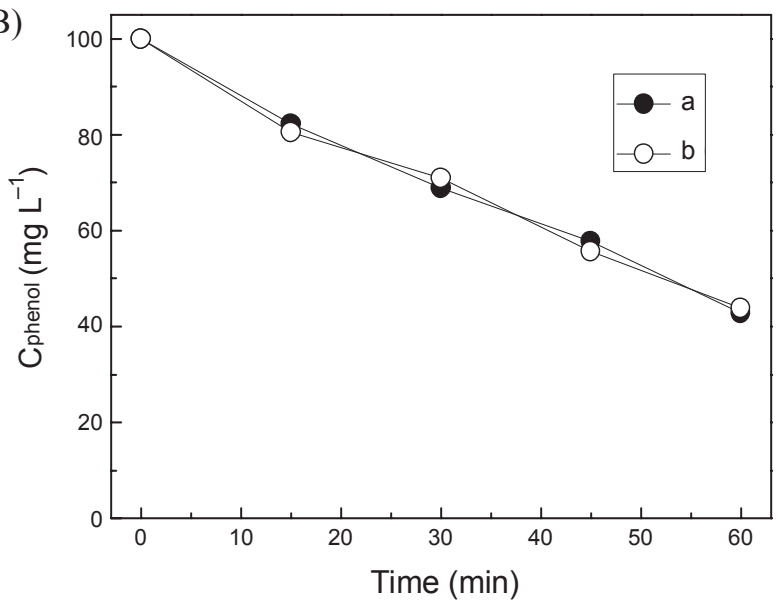

Figure 4. Time evolution of the concentration of phenol at $283 \mathrm{~K}(\mathrm{~A})$ and $313 \mathrm{~K}$ (B) under single ozonation (a) and catalytic ozonation of $\mathrm{Co}_{3} \mathrm{O}_{4}$ nanomaterials (b). Catalyst dose: $0.50 \mathrm{~g}$, volume of simulated wastewater: $200 \mathrm{~mL}$, initial concentration of phenol: $100 \mathrm{mg} \mathrm{L}^{-1}$, flow rate of ozone: $0.40 \mathrm{mg} \mathrm{min}^{-1}$

catalytic degradation of phenol increased from $283 \mathrm{~K}$ to $298 \mathrm{~K}$ may be due to that (2) and (3) played a predominant role. When the temperature increased from $298 \mathrm{~K}$ to $313 \mathrm{~K}$, (1) was the main factor, and the degradation rate of phenol decreased.

After the single ozonation of $60 \mathrm{~min}$ at 283, 298 and $313 \mathrm{~K}$, the removal of phenol were $60.5,65.3$ and $57.3 \mathrm{mg} \mathrm{L}^{-1}$, respectively. While after the catalytic ozonation of $60 \mathrm{~min}$ at 283 , 298 and $313 \mathrm{~K}$, the removal of phenol were 82.6, 90.0 and 56.1 $\mathrm{m} \mathrm{L}^{-1}$. That is, the degradation efficiencies of phenol were increased by about $36.5 \%, 37.8 \%$ and $-2.0 \%$ at 283,298 and $313 \mathrm{~K}$ due to the presence of $\mathrm{Co}_{3} \mathrm{O}_{4}$ nano-catalyst. We can see that the $\mathrm{Co}_{3} \mathrm{O}_{4}$ exhibited evident catalytic activity at 283 and $298 \mathrm{~K}$, while there was not any catalytic activity at $313 \mathrm{~K}$.

Influence of hydroxyl radicals scavenger. According to traditional catalytic ozonation theory, molecular ozone can oxidize organic substances via a direct route or can undergo decomposition via a chain reaction mechanism to produce free hydroxyl radicals. ${ }^{3}$ As is known, tert-butanol can easily react with hydroxyl radicals $\left(\mathrm{k}=6.0 \times 10^{8} \mathrm{M}^{-1} \mathrm{~s}^{-1}\right)$ and hardly react with molecular ozone $\left(\mathrm{k}=3.0 \times 10^{-3} \mathrm{M}^{-1} \mathrm{~s}^{-1}\right)$, it has been widely used as a probe to determine the role of hydroxyl radicals in ozonation. $^{3,17,25,26}$ In our experiment, $1.0 \mathrm{~g}$ of tert-butanol was introduced to $200 \mathrm{~mL}$ of the above reaction system with other reaction conditions kept constant to investigate the influence of hydroxyl radical scavenger on the degradation of phenol.

As can been seen from Fig. 5, tert-butanol demonstrated obviously negative effect on the single ozonation of phenol, while it showed much less negative effect on catalytic ozonation by $\mathrm{Co}_{3} \mathrm{O}_{4}$ nano-catalyst. The results indicated that the transformation from ozone molecules to hydroxyl radicals in catalytic ozonation decreased compared with that in single ozonation. The results also suggested that hydroxyl radicals were not the main oxidant in catalytic ozonation.

Analysis of catalysis ozonation mechanism. Based on the ozonation theory and our experimental results, the catalytic ozonation of phenol in presence of $\mathrm{Co}_{3} \mathrm{O}_{4}$ nanoparticles may be concluded as an oxidation process by ozone molecules: both ozone molecules and pollutants molecules were adsorbed on

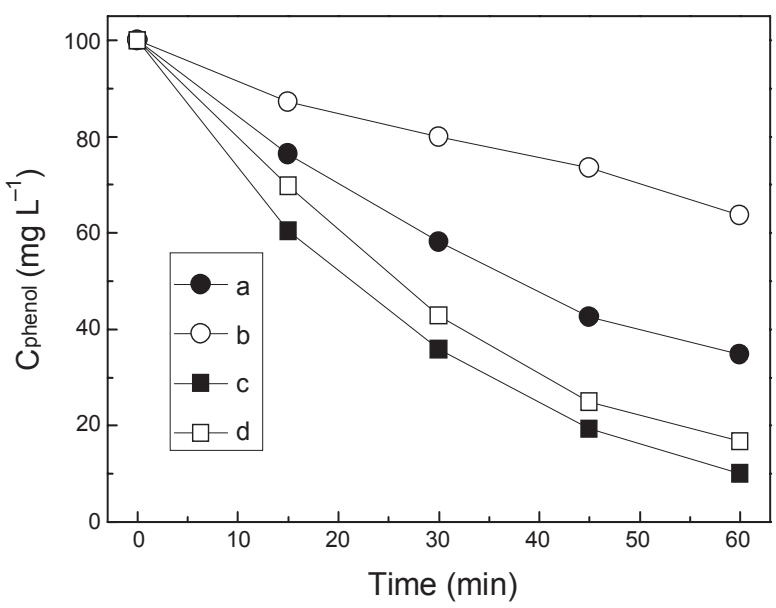

Figure 5. Influence of hydroxyl radicals scavenger (tert-butanol) on the ozonation degradation of phenol. (a) single ozonation, (b) single ozonation + tert-butanol, (c) catalytic ozonation, (d) catalytic ozonation + tert-butanol. Addition of tert-butanol: $1.0 \mathrm{~g}, \mathrm{Co}_{3} \mathrm{O}_{4}$ nano-catalyst dose: $0.50 \mathrm{~g}$, volume of simulated wastewater: $200 \mathrm{~mL}$, initial concentration of phenol: $100 \mathrm{mg} \mathrm{L}^{-1}$, flow rate of ozone: $0.40 \mathrm{mg} \mathrm{min}^{-1}$, reaction temperature: $298 \mathrm{~K}$

the surface of $\mathrm{Co}_{3} \mathrm{O}_{4}$ nano-catalyst, and then pollutants molecules were oxidized by ozone molecules. The adsorption process enhanced the contact probability of ozone molecules and pollutants molecules, and the degradation of pollutants was accelerated. Based on this mechanism, the experimental results shown in Fig. 5 and Fig. 4B could be reasonably explained. Strictly speaking, the ozonation at the surface of nano-catalyst and the aqueous solution can take place simultaneously. In catalytic ozonation, some ozone molecules directly reacted with pollutants on the surface of nano-catalyst. Therefore, as shown in Fig. 5, the transformation from molecular ozone to hydroxyl radicals in aqueous solution decreased. Usually, adsorption is an exothermic equilibrium process. At higher temperature such as $313 \mathrm{~K}$, due to the low concentration of molecular ozone in aqueous solution and thermal effect, the adsorption of ozone 
molecules on solid-liquid interface was restrained. At the same time, the generation of hydroxyl radicals from ozone molecules in aqueous solution was accelerated. Then, the total result was that the degradation rates of phenol were similar in single ozonation and catalytic ozonation at $313 \mathrm{~K}$ (Fig. 4B).

As for the different catalysis properties of $\mathrm{Co}_{3} \mathrm{O}_{4}$ nanoparticles and bulky $\mathrm{Co}_{3} \mathrm{O}_{4}$, the surface state may be an important factor. The crystalline degree of $\mathrm{Co}_{3} \mathrm{O}_{4}$, which was determined by the preparation conditions, influenced the attractive power of surface oxygen atoms for protons. Consequently, the $\mathrm{pH}_{\mathrm{pzc}}$ of two samples were different (the $\mathrm{pH}_{\mathrm{pzc}}$ of $\mathrm{Co}_{3} \mathrm{O}_{4}$ nanoparticles was 6.30, while that of bulky $\mathrm{Co}_{3} \mathrm{O}_{4}$ was 3.75). In aqueous solution, the $\mathrm{pH}_{\mathrm{pzc}}$ of $\mathrm{Co}_{3} \mathrm{O}_{4}$ and the $\mathrm{pH}$ of the solution determined the surface charge states of the catalyst. ${ }^{27}$ The oxide surface becomes protonated or deprotonated when the $\mathrm{pH}$ of the aqueous solution is below or above the $\mathrm{pH}_{\mathrm{pzc}}$, as shown in equation (1) and (2).

$$
\begin{array}{ll}
\mathrm{CoOH}+\mathrm{H}^{+} \leftrightarrow \mathrm{CoOH}_{2}^{+} & \left(\mathrm{pH}<\mathrm{pH}_{\mathrm{pzc}}\right) \\
\mathrm{CoOH}+\mathrm{OH}^{-} \leftrightarrow \mathrm{CoO}^{-}+\mathrm{H}_{2} \mathrm{O} & \left(\mathrm{pH}>\mathrm{pH}_{\mathrm{pzc}}\right)
\end{array}
$$

In our ozonation experiments, the $\mathrm{pH}$ of the solution changed from 6.30 to 3.80 gradually. For $\mathrm{Co}_{3} \mathrm{O}_{4}$ nanoparticles (with $\mathrm{pH}_{\mathrm{pzc}}$ of 6.30), the surface- $\mathrm{OH}_{2}{ }^{+}$should be the predominant surface group. Molecular ozone, which possesses a strong electrophilic and nucleophilic reactivity due to its dipole structure, could interact with the surface- $\mathrm{OH}_{2}{ }^{+}$through two simultaneous attractive forces: electrostatic forces and hydrogen bonding. Obviously, the surface properties of $\mathrm{Co}_{3} \mathrm{O}_{4}$ nanoparticles were advantageous for adsorption of ozone molecules. For bulky $\mathrm{Co}_{3} \mathrm{O}_{4}$, the $\mathrm{pH}$ of the solution was above its $\mathrm{pH}_{\mathrm{pzc}}$, and the surface- $\mathrm{O}^{-}$ should be the predominant surface group. Compared with that of $\mathrm{Co}_{3} \mathrm{O}_{4}$ nanoparticles, the surface of bulky $\mathrm{Co}_{3} \mathrm{O}_{4}$ was absent of attraction forces for molecular ozone. The fewer molecular ozone was adsorbed, the lower catalysis efficiency was obtained by the catalyst. In addition, the surface area, the density of surface hydroxyl groups and the dispersibility of $\mathrm{Co}_{3} \mathrm{O}_{4}$ nanoparticles were greatly higher than those of bulky $\mathrm{Co}_{3} \mathrm{O}_{4}$, which were also important and favorable for the higher catalysis efficiency of $\mathrm{Co}_{3} \mathrm{O}_{4}$ nanoparticles than that of bulky $\mathrm{Co}_{3} \mathrm{O}_{4}$. Of course, the surface area, the density of surface hydroxyl groups and the dispersibility correlate closely with the size of particles.

\section{Conclusion}

The $\mathrm{Co}_{3} \mathrm{O}_{4}$ nano-catalyst exhibited remarkable higher catalysis efficiency on ozonation degradation of phenol and its ozonation intermediates compared with bulky $\mathrm{Co}_{3} \mathrm{O}_{4}$ and ozonation alone. The removal rate of phenol for catalytic ozonation was higher at $298 \mathrm{~K}$ than that of $283 \mathrm{~K}$ and $313 \mathrm{~K}$. The presence of tert-butyl alcohol had little negative effect on catalytic ozonation. These experimental results confirmed the proposition that degradation of phenol by $\mathrm{Co}_{3} \mathrm{O}_{4}$ nanoparticles was through a reaction process between ozone molecules and pollutants on the interface of solid-liquid. The surface state, the higher surface area, the density of surface hydroxyl groups and the well dis- persibility of $\mathrm{Co}_{3} \mathrm{O}_{4}$ nanoparticles were favorable for its higher catalysis efficiency than bulky $\mathrm{Co}_{3} \mathrm{O}_{4}$.

Acknowledgments. The authors gratefully acknowledge the support from the National Natural Science Foundation of China (No. 20903048, 20771046 and 21005031), the Fundamental Research Funds for the Central Universities (No.JUSRP30903), the Startup Foundation for Introduced Talents (No.20081789 and 20091207), the Science Foundation for Youth (No. 2008LQN002 and 2009LQN11).

\section{References}

1. Liotta, L. F.; Gruttadauria, M.; DiCarlo, G.; Perrini, G.; Librando, V. J. Hazard. Mater. 2009, 162, 588.

2. Faria, P. C. C.; Orfao, J. J. M.; Pereira, M. F. R. Catal. Lett. 2009, 127, 195.

3. Kasprzyk-Hordern, B.; Ziółek, M.; Nawrocki, J. Appl. Catal. B: Environ. 2003, 46, 639.

4. Dong, Y.; He, K.; Zhao, B.; Yin, Y.; Yin, L.; Zhang, A. Catal. Commun. 2007, 8, 1599.

5. Jung, H.; Choi, H. Appl. Catal. B: Environ. 2006, 66, 288.

6. Jung, H.; Park, H.; Kim, J.; Lee, J. H.; Hur, H. G.; Myung, N. V.; Choi, H. Environ. Sci. Technol. 2007, 41, 4741.

7. Jung, H.; Kim, J. W.; Choi, H.; Lee, J. H.; Hur, H. G. Appl. Catal. B: Environ. 2008, 83, 208.

8. Yang, Y.; Ma, J.; Qin, Q.; Zhai, X. J. Mol. Catal. A: Chem. 2007, 267,41 .

9. Rosal, R.; Rodríguez, A.; Gonzalo, M. S.; García-Calvo, E. Appl. Catal. B: Environ. 2008, 84, 48.

10. Dong, Y.; Yang, H.; He, K.; Song, S.; Zhang, A. Appl. Catal. B: Environ. 2009, 85, 155.

11. Dong, Y.; He, K.; Yin, L.; Zhang, A. Nanotechnology 2007, 18, 435602 .

12. Zhang, T.; Li, C.; Ma, J.; Tian, H.; Qiang, Z. Appl. Catal. B: Environ. 2008, 82, 131.

13. Laiti, E.; Öhman, L. O.; Nordin, J.; Sjöberg, S. J. Colloid Interface Sci. 1995, 175, 230 .

14. Tamura, H.; Tanaka, A.; Mita, K.; Furuichi, R. J. Colloid Interface Sci. 1999, 209, 225.

15. Stumm, W. Chemistry of the Soild-Water Interface; John Wiley \& Sons: New York, 1992; p 15.

16. Newcombe, G.; Hayes, R.; Drikas, M. Colloid Surface. A 1993, 78,65 .

17. Dong, Y.; Yang, H.; He, K.; Wu, X.; Zhang, A. Appl. Catal. B: Environ. 2008, 82, 163.

18. Bremner, D. H.; Burgess, A. E.; Houllemare, D.; Namkung, K. C. Appl. Catal. B: Environ. 2006 63, 15.

19. Lesko, T.; Colussi, A. J.; Hoffmann, M. R. Environ. Sci. Technol. 2006, 40, 6818.

20. Wu, C.; Liu, X.; Wei, D.; Fan, J.; Wang, L. Water Res. 2001, 35, 3927.

21. Santos, A.; Yustos, P.; Quintanilla, A.; Ruiz, G.; García-Ochoa, F. Appl. Catal. B: Environ. 2005, 61, 323.

22. Santos, A.; Yustos, P.; Quintanilla, A.; Rodriguez, S.; GarcíaOchoa, F. Appl. Catal. B: Environ. 2002, 39, 97.

23. Field, R. J.; Raghavan, N. V.; Brummer, J. G. J. Phys. Chem. 1982, 86,2443

24. Hoigné, J.; Bader, H. Water Res. 1983, 17, 173.

25. Carbajo, M.; Beltrán, F. J.; Medina, F.; Gimeno, O.; Rivas, F. J. Appl. Catal. B: Environ. 2006, 67, 177.

26. Buxton, G. V.; Greenstock, C. L.; Helman, W. P.; Ross, W. P. J. Phys. Chem. Ref. Data 1988, 17, 513.

27. Zhao, L.; Sun, Z.; Ma, J. Environ. Sci. Technol. 2009, 43, 4157. 